\title{
Virtual Organizations: An Overview
}

\author{
Mohammad Reza Nami \\ Faculty of Electrical, Computer, and IT Engineering, \\ Islamic Azad University of Qazvin, IRAN \\ Nami1352@gmail.com
}

\begin{abstract}
The need to remain competitive in the open market forces companies to concentrate on their core competencies while searching for alliances when additional skills or resources are needed to fulfill business opportunities. The changing business situation of companies and customer needs have motivated researchers to introduce Virtual Organization (VO) idea. A Virtual Organization is always a form of partnership and managing partners and handling partnerships are crucial. Virtual organizations are defined as a temporary collection of enterprises that cooperate and share resources, knowledge, and competencies to better respond to business opportunities. This paper presents base concepts of virtual organizations including properties, management concepts, operational concepts, and main issues in collaboration such as security and authentication.
\end{abstract}

Keywords: Collaborative Networks, Virtual Organization, Virtual organization Breeding Environment (VBE), Virtual Enterprise (VE).

\section{Introduction}

Advances in Communication and Internet technology especially Internet services, and trends such as agility, globalization, and increasing demands for products and services with high productivity have motivated different organizations to cooperate and come together to explore business opportunities and fulfill customer tasks. In short, evolution of the Internet and rapid changes in customer demands for extended services and products have motivated organizations toward a new cooperation schema including geographically and legally organizations that collaborate to achieve the goal. This cooperation is supported by computer networks. A Collaborative Network (CN) [1] is an alliance constituted by a variety of entities that are largely autonomous, geographically, distributed, and heterogeneous in terms of their operating environment, culture, social, and goals, but that collabo- 
rate to better achieve common or compatible goals, and whose interactions are supported by computer network. Collaborate Networks are categorized into ad-hoc collaborations and Collaborative Networked Organizations (CNOs). Virtual teams, virtual workspaces, and virtual workers are defined in such extended enterprises. Virtual organizations are a part of goal-oriented CNOs.

\subsection{Reasons and Motivations}

The idea of VO/VE has not been invited by a single researcher rather it is a concept that has matured through a long evolution process. Co-operation between organizations or enterprises is not a new phenomenon too. The terms like virtual company, virtual enterprise, or virtual corporation have been introduced in the early 1990s, including the work of Malone and Davidow [2]. Then, a large body of literature has been produced mainly in two communities, the ICT, and the management. However, concepts and definitions of VO/VE paradigm are still evolving. During last 10-15 years, a large number of research projects have been run in Europe through the European commission funded programs, Japan, USA, Australia, and Mexico [3]. Therefore, research and discussion on virtual organization idea can improve distributed processing.

Virtual Organization has been introduced as a new organizational schema including a temporary set of geographically organizations collaborating sharing skills and resources to fulfill customer requests in a networked environment. Networking can be seen as a proper way to build up co-operation with other organizations. Cost-effective, saving time, high quality, flexibility, agility, and management of risks are some benefits of using network as breeding environment for virtual organizations [4].

\subsection{Structure of the Paper}

This paper is organized as follows. Section 2 presents an overview of virtual organizations and virtual enterprises concepts including different virtual organization including definitions, properties and quality factors. Section 3 discusses the most common issues in a collaborative work environment especially VO management. Finally, conclusion and future work are presented. 


\section{Base concepts} tions.

This section explains different definitions and properties of virtual organiza-

\subsection{VO Definitions}

L. M. Camarinha-Matos, H. Afsarmanesh, and M. Ollus [3] define VO as a "set of co-operating (legally) independent organizations, which to the outside world provide a set of services and act as if they were one organization. It is also reconfigurable. The co-operation is supported by computer networks". T. Dimitrakos et al [5] have also defined VO as "a temporary or permanent coalition of geographically dispersed individual, group, organizational units or entire organizations that pool resources, capabilities, and information to achieve common objectives.

Partners or virtual organization members in a VO should collaborate in order to achieve business opportunities. Important attributes for good partnerships are basic principles of human interaction and business perspectives. Basic principles of human interaction include:

- Fairness: Just to all parties, equitable

- Trust: Reliance on the integrity.

- Integrity: Adherence to a strict moral or ethical code

- Competency: Qualities of features that distinguish a person or group

- Open communication: Exchanging data freely between two partners

Business perspectives include:

- Balance of rewards versus risks or resources required

- Self-interest of both partners

Networks or breeding environments are an appropriate context for effective creation of dynamic VOs.

\subsection{VBE Definitions}

The authors in [6] called this context as Virtual organization Breeding Environment (VBE) and defined it as "an association of organizations and their related supporting institutes, adhering to a base long term cooperation agreement, and adoption of common operating principles and infrastructures, with the main goal of increasing both their chances and their preparedness towards collaboration in potential VOs". 
For each business opportunity found by one of VBE members, acting as a broker, a subset of the VBE enterprises may be chosen to form a VO for that specific business opportunity. VBE also evaluates and coordinates created VO during its life cycle. Each VBE has a life cycle. The aim of a VBE is to improve preparedness of the partners.

Some benefits of VBE include [4,6]:

- Agility in dynamic VO creation

- Facilitating VO reconfiguration

- $\quad$ Providing a bag of assets, resources, tools, policies, and knowledge for better collaborating among members. It also holds the past performance measurements of members for selecting in new virtual organizations

- Managing competencies and reduction of risk in selecting members

- Defining criteria for evaluation of members trust with recording their performance history and introducing methods for building trust among the members

Each VBE serves a specific domain and attempts to select the best members to achieve its specific aims in the domain.

\section{$2.3 \mathrm{VO}$ Benefits}

Some benefits of virtual organizations include saving time such as time to market and reducing development process, spreading costs and risks with partners, improving quality factors such as performance and flexibility, exchange and share knowledge, and marketing in high scale, matching virtual organizations with dynamic changes in marketing, access to new technology and new customers, access to new markets through partnership, and improving access to financial resources. In most cases a mixture of these will be the driver for operating and doing business in networks.

\subsection{VO Properties}

Some basic characteristics of the virtual organization are often referred to $[3,7]$ and described in the following.

Delocalization is potentially space dependence. Therefore, enterprises become independent off space and capacity. It eliminates the need for a particular space. Temporalization refers to inter organizational relations and to the internal process organization, in the sense of the modular and fractal organization. Asynchronous 
causes members to asynchronously communicate and interact with each other via the ICT in the context of innovations with the release of time. NonInstitutionalization of inter-organizational relationships in virtual environments can be waived because operations are performed in an environment without physical attributes. Dematerialization means that all object areas are immaterial. Existing mutual confidence for members, absence of physical attributes and administrator can affect system performance and flexibility. Increasing consumer demands is motivated Individualization property. Mass customization is one approach for manufacturers to fulfill customer demands and capture new markets. Integrative Atomization refers to integrate all atomized core competencies of the participants for satisfying customer.

These properties can be categorized in three groups: product and service, VO conditions and environment, and effective VO operation characteristics. Virtual organization properties also affect quality factors. It is outlined in table 1.

Table1. Relationships between Virtual Organization Properties and Quality Factors (QFs)

\begin{tabular}{ll}
\hline $\begin{array}{l}\text { Virtual Organization Prop- } \\
\text { erties }\end{array}$ & Quality Factors \\
\hline Delocalization & Portability \\
Temporalization & Functionality \\
Asynchronous & Functionality, Efficiency \\
Non-Institutionalization & Portability, Maintainability \\
Individualization & Maintainability, Functionality \\
Integrative Atomization & Reliability, Efficiency \\
Dematerialization & Efficiency, Portability, Flexi- \\
& bility. \\
\hline
\end{tabular}

\section{Virtual Organization Challenges}

This section presents some challenges and trends in virtual organization.

\subsection{Challenges of Virtual Organization Creation}

Since a VO is fixing as a master component of dynamic collaborative networks, there are different issues and challenges in VO creation, management, design, and implementation. Virtual organization life cycle includes three stages: creation, operation along with evolution, and termination. Identifying business opportunities, 
examining the partner competencies, selecting partners from within or outside the VBE (network), forming the best partnership in terms of the competencies, creating the necessary databases, registering new members, and VO setting up are the key tasks in VO creation. Main challenges of VO creation are outlined in the following:

- Negotiation of virtual organization partners (members) includes contract templates, virtual negotiation rooms, and negotiation objects

- Defining roles and responsibilities of VO partners

- Building trust as the base for organization collaboration

- Establishing common interoperability/integration platform

- Comparing and selecting organizations to configure the VO

- Issues related to incompatibility and heterogeneity of information sources

- VO planning [8]: Acquiring basic competency information of organizations and collaboration modalities

- Dynamically configure a new VO from autonomous organizations as VO members

Efficient creation of dynamic VOs [3] requires a proper environment that the members of new VOs are selected in it according to their capabilities and trust among them. The main goal of VBE is to improve the preparedness of its member organizations for efficiently creating VOs.

\subsection{Security Management}

The concept of security in virtual organizations includes confidentiality and integrity of data for secure communication, authentication, and access control to resources. Since the whole VO is as secure as its weakest member organization is, each VO member becomes responsible not only for its own security, but also for security of common resources. Definition of a curity framework is a real challenge. Due to dynamically changing environment, security management becomes a must. Security policies and mechanisms are categorized into three groups: organizational, legal, and technical. Alteration in the organizational structure of institutions and changes in information system configuration make security management a continuous process. Estimating the risk of occurrences of potential threads and their effects, determining and implementing optimal security measures, continuously monitoring the system operations, detecting proper security rules, and running them are main activities of security management [9]. 


\subsection{Competency Management}

Competency of an organization is defined as the validated capability of an organization to perform business processes, in collaboration with associated partners, having available the necessary resources (e.g. human, physical, technological), and applying known practices, with the aim to offer creation services/ products to customers. The competencies allow to perform processes and require resources as input that have product or services as output. The processes are supported by associated partners. The advance functionalities of competency management [10] include as follows:

- Automatically collecting competency data from organizations

- Competency gap analysis: This is based on matching domain competency ontology and a set of competencies existing in the VBE database

- Discovery of new competency in VBE: This is based on matching competencies needed for future business strategy and a set of competencies existing in the VBE database

Competency ontology is a part of the VBE ontology.

\subsection{Trust Management}

To enhance the efficiency and success of both their cooperation within the VBE as well as their collaboration in virtual organizations configured in the VBE, trust [11] is discussed. Some challenges in trust are presented in the following:

- Transparency: Each step taken for entire trust assessment within a VO or a VBE must be clear and transparent to all involved VBE members. Information used must be certified too

- Complexity: The complexity of multi-objective and multi-criteria nature of trust and trust level in VBEs is one of main challenges

- Causality: The future trust level of a VBE member is causally related to its role and behavior at present, and actions it has performed and events it has caused in the past

Trust accelerates collaboration among VBE members, enhances information sharing and knowledge creation, and reduces the management cost and transaction costs between the members [12]. Applying agents in implementation of virtual enterprise [13] and designing trust between them are one of challenges in this context. 


\subsection{Ontology Engineering}

Ontology engineering [2] is discussed in VBEs in order to create virtual organizations. It includes defining classes in the ontology, arranging the classes in a taxonomic hierarchy such as subclass-super class, defining slots (properties and relations) and describing allowed values for them, and filling in the values for slots and instantiation. Ontology elements for a VBE in order to create VOs are found in structured resources such as database schemas, semi-structured resources such as XML pages and dictionaries, and unstructured resources such as related text corpora in general. The ontology is engineered by designing and developing reverse engineering methods for structured resources and developing NL parsers for semi-structured and unstructured resources. Domain experts use testing methodology to incrementally develop ontology. They also verify the ontology.

\section{Conclusion and Future Work}

Virtual organization is becoming a strategic characteristic applicable to any organization without physical, geographical, or structural constraints. Virtual team, virtual workplace, and virtual worker are defined in the extended enterprises. Collaborative networks or breeding environments are the source of virtual organizations. They are used for a long-term supporting network in order to enable efficient collaboration in virtual organizations and handle VO activities. At present, more than 100 existing VBEs for creating, managing, and supporting virtual organizations are studied. CARPI is one of them and includes 2068 members in textile domain [2]. This paper presents an overview of virtual organizations including base concepts and challenges. Implementing an autonomic virtual organization including self-configuration, self-healing, self-protection, and self-optimization in information and resources management is my future research.

\section{ACKNOWLEDGEMENTS}

Mohammad Reza Nami is a PhD researcher in autonomic computing domain. He got a scholarship from the MSRT (Ministry of Science, Research, and Technology) of Iran. He has more than 15 journal and conference papers. He has run many projects in formal methods, software engineering, virtual organizations, and self-managing systems. He has worked at Delft University of Technology with Prof. Stamatis and Dr. Bertels. Some of his research has been supervised by Prof. Afsarmanesh at Amsterdam University. 


\section{REFERENCES}

1. Camarinha-Matos L. M. and Afsarmanesh H., Creation of virtual organizations in a breeding environment, In the Proceedings of INCOM 2006, $12^{\text {th }}$ IFAC Symposium on Information Control Problems Manufacturing, Saint-Etienee, France, May 2006.

2. Davidow W. and Malone T., The Virtual Corporation, Harper Business, 1992.

3. Camarinha-Matos L. M., Afsarmanesh H., and Ollus M., Virtual Organizations: systems and practices, In Springer Science, 2005.

4. Nami M. R. and Tavangarian D. J., Virtual Organizations: A New Approach in IT, The 7th IEEE International Conference on Computer and Information Technology (CIT 2007), Aizu, Japan, October 2007, pp.93-98.

5. Dimitrakos T. et al, Towards a Trust and Contract Management Framework for Dynamic Virtual Organizations, Proceeding of the e-Challenges 2004, Vienna, Austria, October 2004.

6. Afsarmanesh H. and Camarinha-Matos L. M., A framework for management of virtual organization breeding environment, PRO-VE'05, 2005.

7. Karvonen J., Salkari I., and Ollus M., Characterizing virtual organization and their management. In PROVE' 05, September 2005.

8. Camacho R. et al, An integrative approach for VO planning and launching, PRO-VE'05, 2005.

9. Magiera J. and Pawlak A., Security frameworks for Virtual Organizations, In Virtual Organizations, Springer, 2005, pp.133-148.

10. Ermilova E. and Afsarmanesh H., Competency and profiling management in VBEs, in the Proceedings of PRO-VE '06, Springer, Helsinki, Finland, September 2006, pp. 131-143.

11. Haller J., A stochastic approach for trust management. In 22nd International Conference on Data Engineering Workshops (ICDEW'06), Atlanta, GA, USA, April 2006.

12. Msanjila S. S. and Afsarmanesh H., Assessment and Operation of trust in VBEs, in the Proceedings of PRO-VE '06, Springer, Helsinki, Finland, September 2006, pp. 161-173.

13. Guidi-Polanco F., Cubillos C., and Menga G., The global automation platform: An agentbased framework for virtual organizations. in PRO-VE'05, September 2005. 